\title{
How possible is the development of an operational psychometric method to assess the presence of the 5-HTTLPR $s$ allele? Equivocal preliminary findings
}

Xenia Gonda ${ }^{1,2^{*}}$, Konstantinos N Fountoulakis ${ }^{3}$, Zoltan Rihmer ${ }^{2}$, Andras Laszik ${ }^{4}$, Hagop S Akiskal ${ }^{5}$, Gyorgy Bagdy ${ }^{1}$

\begin{abstract}
Objective: The $s$ allele of the 5-hydroxytryptamine transporter-linked promoter region (5-HTTLPR) polymorphism of the serotonin transporter gene has been found to be associated with neuroticism-related traits, affective temperaments and response to selective serotonin reuptake inhibitor (SSRI) treatment. The aim of the current study was to develop a psychometric tool that could at least partially substitute for laboratory testing and could predict the presence of the $s$ allele.

Methods: The study included 138 women of Caucasian origin, mean $32.20 \pm 1.02$ years old. All subjects completed the Hungarian standardised version of the Temperament Evaluation of the Memphis, Pisa, Paris, and San Diego Autoquestionnaire (TEMPS-A) instrument and were genotyped for 5-HTTLPR using PCR. The statistical analysis included the calculation of the Index of Discrimination (D), Discriminant Function Analysis, creation of scales on the basis of the above and then item analysis and calculation of sensitivity and specificity.

Results: Four indices were eventually developed, but their psychometric properties were relatively poor and their joint application did not improve the outcome.

Conclusions: We could not create a scale that predicts the 5-HTTLPR genotype with sufficient sensitivity and specificity, therefore we could not substitute a psychometric scale for laboratory genetic testing in predicting genotype, and also possibly affective disorder characterisation and treatment.
\end{abstract}

\section{Background}

The s allele of the 5-hydroxytryptamine transporter-linked promoter region (5-HTTLPR) polymorphism of the serotonin transporter gene has been shown to be significantly associated with both unipolar, bipolar and subthreshold forms of affective disorder [1-8] and also the neuroticism trait [9-12], indicating a significant role of the polymorphism in the background of affective phenomena and pathology. In a previous paper we described that affective temperaments composing the depressive superfactor (that is, depressive, cyclothymic, anxious and irritable temperaments also show a significant association with the $\mathrm{s}$ allele) [13]. In a more recent paper, we attempted to compose a

\footnotetext{
* Correspondence: kendermagos@yahoo.com

* Correspondence: kendermagos@yahoo.com
'Department of Pharmacodynamics, Semmelweis University, Faculty of Medicine, Budapest, Hungary
} Medicine, Budapest, Hungary

scale of those items of the Temperament Evaluation of the Memphis, Pisa, Paris, and San Diego Autoquestionnaire (TEMPS-A) scale measuring affective temperaments that differentiate most sensitively between subjects carrying and not carrying the s allele, and we managed to derive a scale consisting of nine items that was able to differentiate between the two groups at a good level of significance and also showed good internal consistency [14]. Since the s allele is associated not only with neuroticism and tendency to develop affective disorders in the face of adverse life events, but also with less favourable response to selective serotonin reuptake inhibitors (SSRIs) [15-19], we considered it of interest to develop a scale which could predict presence of the s allele to a high accuracy and thus less likely SSRI response. For this purpose a careful and 
meticulous psychometric approach is needed in delineating and validating the scale.

In the present paper we attempted to delineate and validate a scale based on the TEMPS-A questionnaire to predict the presence of the 5-HTTLPR s allele scale with a different and more rigorous approach.

\section{Methods}

\section{Study participants}

The study population included 138 psychiatrically healthy unrelated Hungarian women of Caucasian origin. All participants were aged between 18-64 years; the mean age of our subjects was $32.20 \pm 1.02$ years. All subjects were screened for neurological and psychiatric disorders using the standardised Hungarian version of the MINI International Neuropsychiatric Interview [20]. Subjects with any neurological and current or lifetime Diagnostic and Statistical Manual of Mental Disorders, fourth edition (DSMIV) Axis I psychiatric disorders were excluded.

The study protocol was reviewed and approved by the Scientific and Research Ethics Committee of the Scientific Health Council of Hungary in charge of genetic experimentation concerning human subjects. All subjects gave written informed consent before participating in the study.

\section{Methodology}

All subjects completed the Hungarian standardised version of the TEMPS-A questionnaire that measures affective temperaments on five scales, the depressive, cyclothymic, irritable, anxious and hyperthymic temperaments $[14,21,22]$.

All subjects were genotyped for 5-HTTLPR by PCR. PCR amplification of 5HTTLPR was performed on genomic DNA extracted from buccal cells [23], and 5HTTLPR genotypes were identified as previously reported [24].

\section{Statistical analysis}

All statistical analyses were carried out using Statistica 7.0 for Windows (Statsoft, Tulsa, OK, USA). In all cases we analysed our data according to the additive model (subjects with either of the three different genotypes: ss, sl, ll), according to the dominant model (subjects carrying the s allele and subjects not carrying the s allele), and according to the recessive model (subjects carrying the $l$ allele vs subjects not carrying the 1 allele).

The first step included the calculation of the equivalent of the degree of difficulty [25] as a measure of an Index of Discrimination (D) in order to identify those items from the TEMPS-A scale that best discriminate groups. The D corresponds to the difference in the percentages in the responses given between two groups. The second step included the development of the scales with weighting the item responses; those with $\mathrm{D}$ above 15 were included in the scales with those with D above 20 weighted with a factor of 2 , while those with $D$ below 20 were weighted with a factor of 1 .

Discriminant function analysis was also used in order to obtain two additional indices that could help in separating groups. All the items with D above 15 were included in this type of analysis.

Item analysis was performed, and the value of Cronbach's $\alpha$ for each scale was calculated. The sensitivity $(\mathrm{Sn})$ and Specificity $(\mathrm{Sp})$ were also calculated.

\section{Results}

In all, 19 (13.76\%) subjects carried the ss genotype, 50 (36.23\%) the 11 and $69(50 \%)$ sl genotype. A total of 88 subjects $(63.77 \%)$ carried the $\mathrm{s}$ allele while 50 subjects (36.23\%) did not carry the s allele. The frequency of the $\mathrm{s}$ allele in our sample was $38.77 \%$ which parallels the results of earlier studies and is representative of the Caucasian population [24]. The distribution of genotypes in our study population followed the Hardy-Weinberg equilibrium $\left(\chi^{2}=0.38934, P=0.8231\right)$.

The various genotype groups (ss, sl and ll) did not differ in age $(P>0.05)$ and they also did not differ concerning all the TEMPS-A subscales (Wilk's $\lambda=0.8833$, $\mathrm{F}=1.63, \mathrm{df}=10,262, P=0.0980)$. However, post hoc comparisons indicated a significant difference in case of

Table 1 Descriptive statistics of the various study groups

\begin{tabular}{|c|c|c|c|c|c|c|c|c|c|c|c|c|c|c|c|}
\hline & \multicolumn{6}{|c|}{ Dominant model: presence vs absence of $s$ allele } & \multicolumn{7}{|c|}{ Recessive model: presence vs absence of I allele } & & \\
\hline & \multicolumn{3}{|c|}{ ss and sl ( $\mathrm{n}=88)$} & \multicolumn{3}{|l|}{ II $(n=50)$} & \multicolumn{3}{|c|}{ sl and II (n = 119) } & \multicolumn{3}{|l|}{ ss $(n=19)$} & \multicolumn{3}{|l|}{ sl $(n=69)$} \\
\hline & Mean \pm SD & Min & Max & Mean \pm SD & Min & Max & Mean \pm SD & Min & Max & Mean \pm SD & Min & Max & Mean $\pm S D$ & Min & Max \\
\hline Depressive & $7.30 \pm 3.18$ & 2 & 16 & $5.98 \pm 2.40$ & 2 & 12 & $6.77 \pm 3.05$ & 2 & 16 & $7.11 \pm 2.56$ & 3 & 11 & $7.35 \pm 3.35$ & 2 & 16 \\
\hline Cyclothymic & $6.23 \pm 4.10$ & 0 & 17 & $4.34 \pm 3.01$ & 0 & 11 & $5.62 \pm 3.92$ & 0 & 17 & $5.05 \pm 3.34$ & 0 & 10 & $6.55 \pm 4.24$ & 0 & 17 \\
\hline Hyperthymic & $10.06 \pm 3.67$ & 1 & 20 & $10.72 \pm 4.53$ & 2 & 22 & $10.36 \pm 4.09$ & 1 & 22 & $9.89 \pm 3.43$ & 4 & 15 & $10.10 \pm 3.75$ & 1 & 20 \\
\hline Irritable & $4.59 \pm 3.53$ & 0 & 15 & $3.30 \pm 2.72$ & 0 & 11 & $4.21 \pm 3.41$ & 0 & 15 & $3.58 \pm 2.63$ & 0 & 9 & $4.87 \pm 3.71$ & 0 & 15 \\
\hline Anxious & $8.20 \pm 5.25$ & 0 & 19 & $5.94 \pm 4.48$ & 0 & 18 & $7.22 \pm 5.10$ & 0 & 19 & $8.42 \pm 4.99$ & 0 & 18 & $8.14 \pm 5.35$ & 0 & 19 \\
\hline II scale & $5.49 \pm 2.85$ & 0 & 11 & $3.24 \pm 2.33$ & 0 & 10 & $4.61 \pm 2.89$ & 0 & 11 & $5.05 \pm 2.88$ & 0 & 11 & $5.61 \pm 2.85$ & 0 & 11 \\
\hline ss scale & $5.20 \pm 2.46$ & 1 & 11 & $4.12 \pm 2.16$ & 0 & 9 & $4.50 \pm 2.25$ & 0 & 11 & $6.74 \pm 2.54$ & 2 & 10 & $6.74 \pm 2.54$ & 2 & 10 \\
\hline
\end{tabular}


Table 2 Discrimination index (D) between the groups according to the dominant model (ss + sl vs II) concerning the Temperament Evaluation of the Memphis, Pisa, Paris, and San Diego Autoquestionnaire (TEMPS-A) items

Dominant model (subjects carrying the s allele vs subjects not carrying the $s$ allele)

\begin{tabular}{|c|c|c|c|}
\hline TEMPS-A item & ss or $\mathrm{sl}(\mathrm{N}=\mathbf{8 8})$ & II (N = 50) & D \\
\hline $107 \mathrm{~A}$ & 51.14 & 28.00 & 23.14 \\
\hline $17 D$ & 59.09 & 36.00 & 23.09 \\
\hline 691 & 45.45 & 26.00 & 19.45 \\
\hline 7D & 46.59 & 28.00 & 18.59 \\
\hline $39 C$ & 36.36 & 20.00 & 16.36 \\
\hline $94 \mathrm{~A}$ & 34.09 & 18.00 & 16.09 \\
\hline 681 & 31.82 & 16.00 & 15.82 \\
\hline $29 C$ & 29.55 & 14.00 & 15.55 \\
\hline $92 \mathrm{~A}$ & 53.41 & 38.00 & 15.41 \\
\hline $27 C$ & 51.14 & 36.00 & 15.14 \\
\hline $15 \mathrm{D}$ & 38.64 & 24.00 & 14.64 \\
\hline $99 \mathrm{~A}$ & 38.64 & 24.00 & 14.64 \\
\hline $110 \mathrm{~A}$ & 52.27 & 38.00 & 14.27 \\
\hline $100 \mathrm{~A}$ & 18.18 & 4.00 & 14.18 \\
\hline $86 \mathrm{~A}$ & 34.09 & 20.00 & 14.09 \\
\hline $89 \mathrm{~A}$ & 34.09 & 20.00 & 14.09 \\
\hline $105 \mathrm{~A}$ & 50.00 & 36.00 & 14.00 \\
\hline $52 \mathrm{H}$ & 50.00 & 36.00 & 14.00 \\
\hline $34 C$ & 31.82 & 18.00 & 13.82 \\
\hline $35 \mathrm{C}$ & 55.68 & 42.00 & 13.68 \\
\hline $87 \mathrm{~A}$ & 29.55 & 16.00 & 13.55 \\
\hline 4D & 19.32 & 6.00 & 13.32 \\
\hline $42 \mathrm{C}$ & 19.32 & 6.00 & 13.32 \\
\hline 641 & 27.27 & 14.00 & 13.27 \\
\hline $22 \mathrm{C}$ & 43.18 & 30.00 & 13.18 \\
\hline 731 & 28.41 & 16.00 & 12.41 \\
\hline $88 \mathrm{~A}$ & 34.09 & 22.00 & 12.09 \\
\hline $24 C$ & 13.64 & 2.00 & 11.64 \\
\hline $12 \mathrm{D}$ & 29.55 & 18.00 & 11.55 \\
\hline $23 C$ & 37.50 & 26.00 & 11.50 \\
\hline 771 & 27.27 & 16.00 & 11.27 \\
\hline $90 \mathrm{~A}$ & 35.23 & 24.00 & 11.23 \\
\hline 711 & 20.45 & 10.00 & 10.45 \\
\hline $33 C$ & 20.45 & 10.00 & 10.45 \\
\hline $40 C$ & 36.36 & 26.00 & 10.36 \\
\hline 661 & 18.18 & 8.00 & 10.18 \\
\hline 21D & 26.14 & 16.00 & 10.14 \\
\hline
\end{tabular}

The capital letter after the item number denotes the TEMPS-A subscale: $\mathrm{A}=$ anxious, $\mathrm{D}=$ depressive, $\mathrm{C}=$ cyclothymic or $\mathrm{I}=$ irritable.
Table 3 Discrimination index (D) between the groups according to the recessive model (ss vs sI + II) concerning the Temperament Evaluation of the Memphis, Pisa, Paris, and San Diego Autoquestionnaire (TEMPS-A) items

Recessive model (subjects carrying the I allele vs subjects not carrying the I allele)

\begin{tabular}{llll}
\hline TEMPS-A item & ss $(\mathbf{N}=\mathbf{1 9})$ & $\mathbf{s l}$ or $\mathbf{I I}(\mathbf{N}=\mathbf{1 1 9})$ & $\mathbf{D}$ \\
\hline $98 \mathrm{~A}$ & 63.16 & 33.61 & 29.54 \\
\hline $57 \mathrm{H}$ & 63.16 & 42.02 & 21.14 \\
\hline $55 \mathrm{H}$ & 84.21 & 63.87 & 20.34 \\
\hline $107 \mathrm{~A}$ & 57.89 & 40.34 & 17.56 \\
\hline 711 & 31.58 & 14.29 & 17.29 \\
\hline $103 \mathrm{~A}$ & 63.16 & 47.06 & 16.10 \\
\hline $89 \mathrm{~A}$ & 42.11 & 26.89 & 15.21 \\
\hline $105 \mathrm{~A}$ & 57.89 & 42.86 & 15.04 \\
\hline $91 \mathrm{~A}$ & 36.84 & 21.85 & 14.99 \\
\hline $87 \mathrm{~A}$ & 36.84 & 22.69 & 14.15 \\
\hline $110 \mathrm{~A}$ & 57.89 & 45.38 & 12.52 \\
\hline $79 \mid$ & 21.05 & 9.24 & 11.81 \\
\hline $33 \mathrm{C}$ & 26.32 & 15.13 & 11.19 \\
\hline $40 \mathrm{C}$ & 42.11 & 31.09 & 11.01 \\
\hline $16 \mathrm{D}$ & 89.47 & 78.99 & 10.48 \\
\hline $99 \mathrm{~A}$ & 42.11 & 31.93 & 10.17 \\
\hline $15 \mathrm{D}$ & 42.11 & 31.93 & 10.17 \\
\hline 7 & & &
\end{tabular}

The capital letter after the item number denotes the TEMPS-A subscale: $\mathrm{A}=$ anxious, $\mathrm{D}=$ depressive, $\mathrm{C}=$ cyclothymic or $\mathrm{I}=$ irritable.

the Depressive, Anxious, Cyclothymic and Irritable subscales. When considering the presence or absence of the $\mathrm{s}$ allele (ss and sl combined vs the ll) then the difference concerning the TEMPS-A subscales was significant (Wilk's $\lambda=0.91, \mathrm{~F}=2.40, \mathrm{df}=5,132, P=0.0403$ ) and concerned all individual subscales except the Hyperthymic (Depressive, Anxious, Cyclothymic, Irritable). The descriptive statistics are shown in Table 1.

The results from the calculation of $\mathrm{D}$ are shown in Tables 2 and 3. The resulting scale from the application of weighting on the selected items is shown in Table 4.

Cronbach's $\alpha$ was 0.48 for the ss and 0.66 for the 11 scale. All items were more or less equal and omission of any of them did not alter the $\alpha$ value significantly.

The calculation of sensitivity (Sn) and specificity (Sp) at various cut-off levels for the two scales is shown in Table 5. The discriminant function analysis results are shown in Table 6. Both Sn and Sp as well as the discriminant function analysis results are poor and can not lead to the identification of cases. The combined use of these indices led to poor results as well since no case 
Table 4 Scale resulting from the application of weighting on the selected items of the TEMPS-A/5-hydroxytryptamine (5-HT) s allele subscale

\begin{tabular}{lll}
\hline Item & Criteria & Scoring \\
\hline 7D & I have always blamed myself for what others might consider no big deal & True $=1$, False $=0$ \\
\hline 17D & I would rather work for someone else than be the boss & True $=1$, False $=0$ \\
\hline $27 \mathrm{C}$ & I often blow up at people and then feel guilty about it & True $=1$, False $=0$ \\
\hline 29C & My mood often changes for no reason & True $=1$, False $=0$ \\
\hline $39 \mathrm{C}$ & I am the kind of person who can be sad and happy at the same time & True $=1$, False $=0$ \\
\hline $55 \mathrm{H}$ & I love to be with a lot of people & True $=1$, False $=0$ \\
\hline $57 \mathrm{H}$ & I am known to be generous, and spend a lot of money on other people & True $=1$, False $=0$ \\
\hline $68 \mid$ & I often feel on edge & True $=1$, False $=0$ \\
\hline $69 \mid$ & I often feel wound up & True $=1$, False $=0$ \\
\hline $71 \mid$ & I often get so mad that I will just trash everything & True $=1$, False $=0$ \\
\hline $89 \mathrm{~A}$ & Many people have told me not to worry so much & True $=1$, False $=0$ \\
\hline $92 \mathrm{~A}$ & I often feel jittery inside & True $=1$, False $=0$ \\
\hline $94 \mathrm{~A}$ & I often have an upset stomach & True $=1$, False $=0$ \\
\hline $98 \mathrm{~A}$ & When someone is late coming home, I fear they have had an accident & True $=1$, False $=0$ \\
\hline $103 \mathrm{~A}$ & I am, by nature, a very cautious person & True $=1$, False $=0$ \\
\hline $105 \mathrm{~A}$ & I easily get headaches when stressed & True $=1$, False $=0$
\end{tabular}

Index 1 (ss subscale): $2 \times$ item $55+2 \times$ item $57+$ item $71+$ item $89+2 \times$ item $98+$ item $103+$ item $105+$ item 107 . Interpretation: score $>6$, highly likely for being an SS.

Index 2 (II subscale): $2 \times$ item $107+2 \times$ item $17+$ item $69+$ item $7+$ item $39+$ item $94+$ item $68+$ item $29+$ item $92+$ item 27 . Interpretation: index 2 : score $>3$, highly unlikely for being an SS.

Index 3: If $1.19 \times$ item $55+0.77 \times$ item $57+0.94 \times$ item $71+0.14 \times$ item $89+1.14 \times$ item $98+0.36 \times$ item $103-0.02 \times$ item $105+0.53 \times$ item $107-4.38<0$ then it is highly unlikely to be an SS.

Index 4: If $0.09 \times$ item $7+0.89 \times$ item $17+0.34 \times$ item $27+0.40 \times$ item $29+0.79 \times$ item $39+0.39 \times$ item $68+0.26 \times$ item $69+0.09 \times$ item $92+0.26 \times$ item $94+0.68 \times$ item $107-0.91<0$ then it is highly likely to be either an SS or SL.

seemed to be classified by all the indices to the same allele category.

All scales and indices correlated moderately but significantly with all TEMPS-A subscales (Table 7).

\section{Discussion}

In the present work we attempted to extract a scale from the TEMPS-A questionnaire that would predict the presence of the s allele of the 5-HTTLPR with satisfactory sensitivity and specificity. However, although several items discriminate between the different genotype groups to a high degree, no scale compiling these items showed high sensitivity and specificity with respect to the presence of the $s$ allele. Even the combination of the scales that were derived cannot improve the poor classification outcome.

To understand the nature of psychometric disorders and to make more efficient treatment possible, we must not only view these disorders as complex entities in the context of their social, cultural, neurochemical and genetic determinants, but we should also be able to decompose psychiatric disorders into smaller and better characterisable components. The concept of endophenotypes was introduced to aim at identifying and characterising small, atomic phenomena that correspond to an accurately characterisable biochemical process or marker, such as a genetic polymorphism, and which is at the same time highly relevant in the manifestation of psychological phenomena or psychiatric disorders. There is an expanding effort to identify traits and temperaments related to the development of psychiatric illnesses and associate them with genetic factors. Studies have attempted to link psychological traits as measured by psychometric scales with a given polymorphism. Our approach in this case was different: based on an association we had already described between the 5-HTTLPR s allele and several affective temperaments measured by TEMPS-A $[13,26]$, we aimed to construct a scale which would show a high ability to predict 5-HTTLPR genotype.

In a previous paper we attempted to solve the task of delineating a psychometric scale to predict presence of the $s$ allele by selecting the items which differentiated between the different genotype groups using analysis of variance (ANOVA) and performing a subsequent item analysis [14]. In the current paper, however, we used a more rigorous statistical approach in selecting the items differentiating between the different genotype groups and calculated also sensitivity and specificity. As a result, 
Table 5 Sensitivity and specificity of the two scales in discriminating between subjects carrying and not carrying the $s$ allele

\begin{tabular}{|c|c|c|c|c|c|c|}
\hline Score level & TP & $\mathrm{TN}$ & FP & FN & Sensitivity & Specificity \\
\hline \multicolumn{7}{|c|}{$\begin{array}{l}\text { ss scale (subjects carrying the I allele vs subjects not carrying the I } \\
\text { allele): }\end{array}$} \\
\hline $4 / 5$ & 15 & 62 & 57 & 4 & 78.95 & 52.10 \\
\hline $5 / 6$ & 13 & 81 & 38 & 6 & 68.42 & 68.07 \\
\hline $5 / 6$ & 13 & 81 & 38 & 6 & 68.42 & 68.07 \\
\hline $6 / 7$ & 11 & 97 & 22 & 8 & 57.89 & 81.51 \\
\hline
\end{tabular}

II scale (subjects carrying the $\mathrm{s}$ allele vs subjects not carrying the $\mathrm{s}$ allele):

\begin{tabular}{lllllll}
\hline $3 / 4$ & 18 & 24 & 64 & 32 & 94.74 & 20.17 \\
\hline $4 / 5$ & 12 & 37 & 51 & 38 & 63.16 & 31.09 \\
\hline $5 / 6$ & 7 & 48 & 40 & 43 & 36.84 & 40.34 \\
\hline
\end{tabular}

The ss scale discriminates between ss and combined sl and II carriers (subjects carrying vs subjects not carrying the I allele; recessive model). The II scale discriminates between II and combined ss and sl carriers (subjects carrying the $s$ allele vs subjects not carrying the $s$ allele; dominant model). $\mathrm{FN}=$ false negative; $\mathrm{FP}=$ false positive; $\mathrm{TN}=$ true negative; $\mathrm{TP}=$ true positive

Table 6 Discriminant function analysis and development of the discriminating functions

\begin{tabular}{llllllll}
\hline \multicolumn{1}{l}{ ss scale } & \multicolumn{7}{c}{ II scale } \\
\hline & Correct (\%) & sl or II & ss & & Correct (\%) & sl or ss & II \\
\hline ss & 15.79 & 3 & 16 & I| & 56 & 28 & 22 \\
\hline sl or II & 99.16 & 1 & 118 & ss or sl & 85.23 & 13 & 75 \\
\hline Total & 87.68 & 4 & 134 & Total & 74.64 & 41 & 97 \\
\hline
\end{tabular}

The ss scale discriminates between ss and combined sl and II carriers (recessive model). The II scale discriminates between II and combined ss and sl carriers (dominant model).

Function for II scale: $0.09 \times$ item $7+0.89 \times$ item $17+0.34 \times$ item $27+0.40 \times$ item $29+0.79 \times$ item $39+0.39 \times$ item $68+0.26 \times$ item $69+0.09 \times$ item $92+$ $0.26 \times$ item $94+0.68 \times$ item $107-0.91<0$ then it is either an ss or sl genotype. Function for ss scale: $1.19 \times$ item $55+0.77 \times$ item $57+0.94 \times$ item $71+0.14 \times$ item $89+1.14 \times$ item $98+0.36 \times$ item $103-0.02 \times$ item $105+0.53 \times$ item 107 $-4.38<0$ then it is NOT an ss genotype.

Table 7 Correlation matrix among the developed scales (II subscale and ss subscale) and the TEMPS-A subscales

\begin{tabular}{lllll}
\hline & Il subscale & ss subscale & Index $\mathbf{3}$ & Index 4 \\
\hline TEMPS-A Depressive & 0.64 & 0.38 & 0.27 & 0.57 \\
\hline TEMPS-A Cyclothymic & 0.65 & 0.41 & 0.40 & 0.64 \\
\hline TEMPS-A Hyperthymic & -0.17 & 0.18 & 0.27 & -0.17 \\
\hline TEMPS-A Irritable & 0.48 & 0.34 & 0.39 & 0.46 \\
\hline TEMPS-A Anxious & 0.71 & 0.66 & 0.53 & 0.58 \\
\hline
\end{tabular}

All values are significant at $P<0.05$.

we could not derive a scale that would predict the presence of the s allele with adequate accuracy.

The role of genetic factors in the background of personality, vulnerability and consequently psychiatric disorders has gained more recognition and wider acceptance in modern times. It is well accepted that the 5-HTTLPR s allele has a profound role in determining the emergence of neuroticism-related personality traits [9-12,27] and psychiatric disorders as well $[1,2,4]$. It has also been suggested and described in several studies that the presence of the $s$ allele not only makes one more likely to possess personality traits which are associated with psychiatric diseases, especially anxiety and affective disorders, but it also makes a less favourable response to SSRI antidepressants more likely [15-17,28-31]. Understanding the underlying biological and personality factors profoundly shapes and reorganises how we view psychiatric disorders today and how they will be classified in the future. Also, these factors should be taken into consideration when selecting the appropriate treatment. Although genetic testing is an available and affordable procedure nowadays, it is not widely used due to several reasons including ethical factors. Moreover, the presence of a given polymorphic allele does not predict the manifestation of a given disorder, only indicates an increased risk. Similar is the case for drug response associated with genetic factors. Therefore a psychometric scale, which is short and easy to administer, and is able to predict presence of the genotype associated with certain personality factors, psychiatric disorders or response to drugs with a great specificity and sensitivity would be a useful tool not only in research but also in everyday psychiatric practice. In our study, however, we failed to develop such a scale, which indicates that as yet we have no accurate and useful psychometric tools that can substitute for biochemical laboratory testing. However, we report these scales in the current study in order to serve as a guide for future research and as they give a gross impression of the psychometric features associated with each genetic category.

In interpreting our results and drawing our conclusions, several limiting factors must be taken into consideration. First of all, our sample was relatively small; studies using larger samples would detect minor differences to a greater accuracy. Also, our sample consisted entirely of women. Further studies are needed to investigate the possibility of extracting a psychometric scale for predicting the $\mathrm{s}$ allele in men and in a mixed-gender general study population.

\section{Conclusions}

Genetic polymorphisms influence not only the emergence of psychiatric diseases but also the pharmacotherapeutic response of these disorders to treatment. Although genetic polymorphisms only mildly contribute to such phenotypical alterations, they may be taken into account when selecting a pharmacological agent. A scale closely related to a given polymorphism may thus be a useful clinical tool, however, the development of such a scale needs further research. 


\section{Acknowledgements}

These studies were supported by the Sixth Framework Programme of the EU, LSHM-CT-2004-503474.

\section{Author details}

'Department of Pharmacodynamics, Semmelweis University, Faculty of Medicine, Budapest, Hungary. ${ }^{2}$ Department of Clinical and Theoretical Mental Health, Semmelweis University, Faculty of Medicine, Budapest, Hungary. ${ }^{3}$ Third Department of Psychiatry, Aristotle University, University Hospital AHEPA, Thessaloniki, Greece. ${ }^{4}$ Institute of Forensic Medicine, Semmelweis University, Faculty of Medicine, Budapest, Hungary. ${ }^{5}$ Department of Psychiatry, University of California at San Diego, La Jolla, CA, USA.

\section{Authors' contributions}

XG conceived the study, gathered and managed the data, performed the genetic analysis, participated in the statistical analysis and wrote the paper. KNF conceived the study, carried out the literature search and analysis and participated in writing the paper. ZR participated in analysing the data and writing the paper. AL participated in the genetic and statistical analysis. HSA participated in designing the study, analysing the data and writing the paper. GB participated in designing the study, analysing the data and writing the paper. All authors read and approved the final manuscript.

\section{Competing interests}

The authors declare that they have no competing interests.

Received: 24 February 2010 Accepted: 7 May 2010

Published: 7 May 2010

\section{References}

1. Bellivier F, Henry C, Szoke A, Schurhoff F, Nosten-Bertrand M, Feingold t, Launay JM, Leboyer M, Laplanche JL: Serotonin transporter gene polymorphisms in patients with unipolar or bipolar depression. Neurosci Lett 1998, 255:143-146.

2. Bellivier F, Leroux M, Henry C, Rayah F, Rouillon F, Laplanche JL, Leboyer M: Serotonin transporter gene polymorphism influences age at onset in patients with bipolar affective disorder. Neurosci Lett 2002, 334:17-20.

3. Brieger P, Roettig S, Ehrt U, Wenzel A, Bloink R, Marneros A: TEMPS-a scale in 'mixed' and 'pure' manic episodes: new data and methodological considerations on the relevance of joint anxious-depressive temperament traits. J Affect Disord 2003, 73:99-104.

4. Collier DA, Stöber G, Li T, Heils A, Catalano M, Di Bella D, Arranz MJ, Murray RM, Vallada HP, Bengel D, Müller CR, Roberts GW, Smeraldi E, Kirov G, Sham P, Lesch KP: A novel functional polymorphism within the promoter of the serotonin transporter gene: possible role in susceptibility to affective disorders. Mol Psychiatry 1996, 1:453-460.

5. Kendler KS, Gatz M, Gardner CO, Pedersen NL: Personality and major depression: a Swedish longitudinal, population-based twin study. Arch Gen Psychiatry 2006, 63:1113-1120.

6. Gonda X, Juhasz G, Laszik A, Rihmer Z, Bagdy G: Subthreshold depression is linked to the functional polymorphism of the $5 \mathrm{HT}$ transporter gene. J Affect Disord 2005, 87:291-297.

7. Levinson DF: The genetics of depression: a review. Biol Psychiatry 2006, 60:84-92.

8. Lotrich FE, Pollock BG: Meta-analysis of serotonin transporter polymorphisms and affective disorders. Psychiatr Genet 2004, 14:121-129.

9. Katsuragi S, Kunugi H, Sano A, Tsutsumi T, Isogawa K, Nanko S, Akiyoshi J: Association between serotonin transporter gene polymorphism and anxiety-related traits. Biol Psychiatry 1999, 45:368-370.

10. Lesch KP, Bengel D, Heils A, Sabol SZ, Greenberg BD, Petri S, Benjamin J, Muller CR, Hamer DH, Murphy DL: Association of anxiety-related traits with a polymorphism in the serotonin transporter gene regulatory region. Science 1996, 274:1527-1531.

11. Melke J, Landen M, Baghei F, Rosmond R, Holm G, Bjorntorp P, Westberg L, Hellstrand M, Eriksson E: Serotonin transporter gene polymorphisms are associated with anxiety-related personality traits in women. Am J Med Genet 2001, 105:458-463.

12. Sen S, Burmeister M, Ghosh D: Meta-analysis of the association between a serotonin transporter promoter polymorphism (5-HTTLPR) and anxietyrelated personality traits. Am J Med Genet B Neuropsychiatr Genet 2004, 127:85-89.

13. Gonda X, Rihmer Z, Zsombok T, Bagdy G, Akiskal KK, Akiskal HS: The $5 H T T L P R$ polymorphism of the serotonin transporter gene is associated with affective temperaments as measured by TEMPS-A. J Affect Disord 2006, 91:125-131.

14. Rózsa S, Rihmer Z, Gonda X, Szili I, Rihmer A, Ko N, Németh A, Pestality P, Bagdy G, Alhassoon O, Akiskal KK, Akiskal HS: A study of affective temperaments in Hungary: internal consistency and concurrent validity of the TEMPS-A against the TCI and NEO-PI-R. J Affect Disord 2008, 106:45-53.

15. Murphy GM Jr, Hollander SB, Rodrigues HE, Kremer C, Schatzberg AF: Effects of the serotonin transporter gene promoter polymorphism on mirtazapine and paroxetine efficacy and adverse events in geriatric major depression. Arch Gen Psychiatry 2004, 61:1163-1169.

16. Pollock BG, Ferrell RE, Mulsant BH, Mazumdar S, Miller M, Sweet RA, Davis $S$, Kirshner MA, Houck PR, Stack JA, Reynolds CF, Kupfer DJ: Allelic variation in the serotonin transporter promoter affects onset of paroxetine treatment response in late-life depression. Neuropsychopharmacology 2000, 23:587-590.

17. Serretti $A$, Kato $M$, De Ronchi $D$, Kinoshita T: Meta-analysis of serotonin transporter gene promoter polymorphism (5-HTTLPR) association with selective serotonin reuptake inhibitor efficacy in depressed patients. Mol Psychiatry 2007, 12:247-257.

18. Smeraldi E, Zanardi R, Benedetti F, Di Bella D, Perez J, Catalano M: Polymorphism within the promoter of the serotonin transporter gene and antidepressant efficacy of fluvoxamine. Mol Psychiatry 1998, 3:508-511.

19. Zanardi R, Benedetti F, Di Bella D, Catalano M, Smeraldi E: Efficacy of paroxetine in depression is influenced by a functional polymorphism within the promoter of the serotonin transporter gene. J Clin Psychopharmacol 2000, 20:105-107.

20. Balazs J, Bitter I, Hideg K, Vitrai J: A MINI és a MINI Plusz kérdōív magyar nyelvû változatának kidolgozása. (Development of the Hungarian version of the M.I.N.I. and M.I.N.I. Plus questionnaires.). Psychiatria Hungarica 1998, 13:160-168.

21. Rozsa S, Rihmer A, Ko N, Gonda X, Szili I, Szadoczky E, Pestality P, Rihmer Z: Az affektív temperamentum: a TEMPS-A kérdōívvel serzett hazai tapasztalatok. Psychiatria Hungarica 2006, 21:147-160.

22. Akiskal HS, Akiskal KK: TEMPS: Temperament Evaluation of Memphis, Pisa, Paris and San Diego (Special Issue). J Affect Disord 2005, 85:1-242.

23. Walsh PS, Metzger DA, Higuchi R: Chelex 100 as a medium for simple extraction of DNA for PCR-based typing from forensic material. Biotechniques 1991, 10:506-513.

24. Heils A, Teufel A, Petri S, Stober G, Riederer P, Bengel D, Lesch KP: Allelic variation of human serotonin transporter gene expression. $J$ Neurochem 1996, 66:2621-2624.

25. Anastasi A: Psychological Testing New York, USA: Macmillan Publishing Company, 61988.

26. Gonda X, Fountoulakis KN, Rihmer Z, Lazary J, Laszik A, Akiskal KK Akiskal HS, Bagdy G: Towards a genetically validated new affective temperament scale: a delineation of the temperament 'phenotype' of 5HTTLPR using the TEMPS-A. J Affect Disord 2009, 112:19-29.

27. Mazzanti CM, Lappalainen J, Long JC, Bengel D, Naukkarinen H, Eggert M, Virkkunen M, Linnoila M, Goldman D: Role of the serotonin transporter promoter polymorphism in anxiety-related traits. Arch Gen Psychiatry 1998, 55:936-940.

28. Smits KM, Smits LI, Peeters FP, Schouten JS, Janssen RG, Smeets HJ, van Os J, Prins MH: The influence of 5-HTTLPR and STin2 polymorphisms in the serotonin transporter gene on treatment effect of selective serotonin reuptake inhibitors in depressive patients. Psychiatr Genet 2008, 18:184-190, 
29. Kesebir S, Vahip S, Akdeniz F, Yuncu Z, Alkan M, Akiskal H: Affective temperaments as measured by TEMPS-A in patients with bipolar I disorder and their first-degree relatives: a controlled study. J Affect Disord 2005, 85:127-133.

30. Lee R, Coccaro E: The neuropsychopharmacology of criminality and aggression. Can J Psychiatry 2001, 46:35-44.

31. Lesch KP, Gutknecht L: Pharmacogenetics of the serotonin transporter. Prog Neuropsychopharmacol Biol Psychiatry 2005, 29:1062-1073.

doi:10.1186/1744-859X-9-21

Cite this article as: Gonda et al:: How possible is the development of an operational psychometric method to assess the presence of the 5HTTLPR $s$ allele? Equivocal preliminary findings. Annals of General Psychiatry 2010 9:21.

\section{Submit your next manuscript to BioMed Central} and take full advantage of:

- Convenient online submission

- Thorough peer review

- No space constraints or color figure charges

- Immediate publication on acceptance

- Inclusion in PubMed, CAS, Scopus and Google Scholar

- Research which is freely available for redistribution

Submit your manuscript at www.biomedcentral.com/submit 